\title{
Postpartum Depressive Symptoms during the Beginning of the COVID-19 Pandemic: An Examination of Population Birth Data from Central New Jersey
}

\author{
Michael J. McFarland ${ }^{1}\left[\right.$ ] Cheryl A. S. McFarland ${ }^{2} \cdot$ Terrence D. Hill $^{3} \cdot$ Robyn D'Oria $^{2}$ \\ Accepted: 31 December 2020 / Published online: 25 January 2021 \\ ○ The Author(s), under exclusive licence to Springer Science+Business Media, LLC part of Springer Nature 2021
}

\begin{abstract}
Objectives To examine the mental health of women in the perinatal period prior to and during the COVID-19 pandemic. Methods We use provisional vital statistics data for births occurring in the central region of New Jersey. The Edinburgh Postnatal Depression Scale is employed to assess depressive symptoms. Our focal analysis uses linear regression models to test whether giving birth during the pandemic is associated with elevated depressive symptoms. All analyses are performed using time-matched (September 2019-April 2020; $\mathrm{n}=18,531$ ) and month-matched (January 2019-April 2019 and January 2020- April 2020; $\mathrm{n}=18,346)$ samples.

Results Women who gave birth in March and not in April reported higher levels of depressive symptoms than those who gave birth prior to the pandemic in our time-matched $(b=0.09)$ and month-matched $(b=0.09)$ samples. The magnitude of this association is approximately one-third the magnitude of the association between preterm birth and depressive symptoms. Conclusion These findings suggest that researchers and practitioners should pay special attention to signs of postpartum depression and women's adaptive coping responses in the early stages of pandemics.
\end{abstract}

Keywords Postpartum depression · COVID-19 - Antenatal screening $\cdot$ Vital statistics

\section{Significance Statement}

What is already known on this subject? There is some evidence for an association between low socioeconomic status, acute and chronic stressors, poor health and increased risk of postpartum depression. What this study adds? Giving birth during the early months of the pandemic increased

Supplementary Information The online version contains supplementary material available athttps://doi.org/10.1007/s1099 5-020-03116-w.

Michael J. McFarland

mmcfarland@fsu.edu

1 Department of Sociology and Center for Demography and Population Health, Florida State University, 113 Collegiate Loop, P.O. Box 3062270, Tallahassee, FL 32306-2270, USA

2 Central Jersey Family Health Consortium, North Brunswick Township, USA

3 Department of Sociology, University of Texas, San Antonio, USA women's risk of developing postpartum depression. Greater understanding of the relationship between acute and chronic stressors associated with public health emergencies provides an insight into challenges faced by this vulnerable population and opportunities for targeted programming and interventions.

\section{Introduction}

The mental health of pregnant and postpartum women is a major public health concern. Between 9 and 13\% of women report depressive symptoms during pregnancy and the postpartum period (Bauman et al. 2020; Haight et al. 2019). Postpartum depression can overwhelm entire families because it contributes to a broad range of emotional, physiological, and behavioral problems across time (women), generations (children), and social relationships (partners) (Businelle et al. 2012; Downs et al. 2008; Matthey et al. 2001; O'Hara 2009; Wisner et al. 2006). Although women regularly experience symptoms related to baby blues after birth, the risk of postpartum depression is notably higher 
under the conditions of low socioeconomic status (unemployment and financial strain), stressful life events (e.g. divorce and death of a loved one), chronic stressors (e.g. social isolation and difficulties with child care), and poor health (e.g. history of mental illness and sleep disturbance) (Bauman et al. 2020; O'Hara 2009; Wisner et al. 2006; Grote and Bledsoe 2007; Robertson et al. 2004; Swendsen and Mazure 2006; Yim et al. 2015).

In this paper, we build on previous research by formally testing whether women who give birth during the novel coronavirus (COVID-19) pandemic are especially vulnerable to symptoms of postpartum depression. In the first several weeks of the pandemic, the issue of pandemic pregnancies have received a great deal of media attention. On March 30, NPR reported that "Pregnant Women Worry about Pandemic's Impact on Labor, Delivery and Babies" (Pfeiffer 2020). On April 28, The New York Times advised "Don't be Afraid of Giving Birth in a New York Hospital" (McClelland 2020). On May 5, Vogue suggested that "You See Your Smallness" when giving birth during a pandemic (Stein 2020). While making comparisons to "The Handmaid's Tale" and "post-apocalyptic times," women described their pandemic pregnancies as "stressful," "isolated," "lonely," "chaotic," "eerie," and "upside down" (Pfeiffer 2020; Stein 2020; Almond 2020; Martin 2020; Sinha 2020). When asked to conceive of a future with her newborn girl, one woman described her suffering in the following way: "The future, I have no idea. I just wait and see. I don't feel deep terror. I just feel sadness" (Knoll 2020). Although clearly not representative of the range of birth experiences in this country, all of these accounts (and many more like them) seem to support the same general conclusion: Giving birth during a pandemic is especially depressing.

In our review of the literature, we could find only two peer-reviewed studies relevant to our focus on pandemics and postpartum depression. The first study reviewed various health care solutions to the challenges of giving birth when health systems are "stressed to their maximum" RoccaIhenacho and Alonso 2020). The authors speculated that depression during the postpartum period may be "exacerbated in times when social isolation is enforced." The second study used data collected from an online survey of 260 pregnant women being treated in a private medical center to assess associations between self-reported pandemic vulnerabilities and scores on the Edinburgh Postnatal Depression Scale (Durankus and Aksu 2020). Their analyses showed that pregnant women who believed that (a) the "COVID19 pandemic" had affected their "psychological health" and (b) "the social isolation" of the pandemic had affected their "psychological wellbeing" tended to exhibit higher levels of postpartum depressive symptoms than pregnant women who did not perceive these vulnerabilities. Although these studies are original and informative, they are both limited empirically. The first study is a policy reflection, so no data are offered to support any claims about the emotional experiences of women. The second study offers new data, but the analysis is undermined by a small convenience sample and the potential common method variance of self-reported pandemic vulnerability and depression. Small convenience samples are limited because they restrict external validity or population health inferences. Common method variance calls into question the internal validity or causal relationship of any association between self-reports derived from the same respondent. In this case, any association between self-reported pandemic stress and self-reported depression could be interpreted as an artifact of their common method of measurement (i.e., response bias) rather than a true association of the supposed underlying concepts.

In the pages that follow, we use data collected through New Jersey Vital Statistics over two years to model monthly variations in postpartum depression scores. Our analyses extend previous work by employing population-level data and avoiding common-method variance by empirically isolating pandemic birth experiences. In accordance with previous research linking stressful conditions and social isolation with postpartum depression, we expect to find that women who gave birth during the novel coronavirus (COVID-19) pandemic will tend to exhibit higher levels of postpartum depression than women who gave birth at previous points during the study period.

\section{Methods}

We utilize the New Jersey Vital Statistics provisional birth file for all live births occurring in the central region of New Jersey in 2019 and early 2020 for this study. Births occurring in March and April 2020 are treated as the first wave of pandemic exposures. New Jersey was the first state to require postpartum depression screening of women who had recently given birth. The New Jersey Postpartum Depression Act requires that health care professionals educate women and their families about postpartum depression, both before and after delivery. The law instructs licensed health care professionals providing postnatal care including physicians and midwives, to screen women for symptoms before they are discharged from the hospital, and again at "the first few" postpartum follow-up visits (Kozhimannil et al. 2011). Women completed the Edinburgh Postnatal Depression Scale (EPDS) prior to discharge from the birth hospitalization. The widely used 10 -item scale has been validated for use across multiple populations (Cox et al. 1987; Gibson et al. 2009). The EPDS asks questions pertaining to depressive symptoms (e.g., "I have felt sad or miserable." "I have been so unhappy that I have been crying."). Original response categories range from 0 (not at all) to 3 (all 
the time) and were summed such that higher scores indicate higher levels of postpartum depressive symptoms. New Jersey tracks the total depressive symptomology score for all births.

Our primary methodological aim is to isolate the effects of pandemic exposure on depressive symptoms. To accomplish this, we must account for alternative explanations or threats to causal inference. On the one hand, we are fortunate that the coronavirus pandemic is an exogenous event that is independent of the factors that contributed to the pregnancies and births in our study population. The idea is that the pandemic had no impact on these reproductive events because all of the women in our study became pregnant long before the first case of COVID-19 was ever observed in China. This property is methodologically advantageous because it excludes the possibility that the pandemic could have somehow systematically contributed to less healthy pregnancies, which could also impact subsequent depressive symptoms. In this case, the pandemic may only impact the experience of women who gave birth after the pandemic was known to the general public. On the other hand, we are concerned that any changes in depressive symptoms occurring during the pandemic could be coincidental because they happen to overlap or coincide with ongoing trends toward greater depression or seasonal/monthly variations in symptoms. The idea here is that some other event or process, seasonal or otherwise, would have contributed to the same changes in depressive symptoms, even if the pandemic had never occurred. We address these possibilities in two ways. First, we employ a time-matched sample that includes the immediate six months prior to the pandemic, estimate month-specific effects that account for any time trends in depressive symptoms prior to the pandemic, and control for sociodemographic and health-related correlates of depressive symptoms (see below). Second, we replicate all analyses with a month-matched sample that employs data from January-April of both 2019 and 2020. While time-matched samples have several methodological advantages, they do not account for seasonal or monthly variations in depressive symptoms. The month-matched sample will assess these variations. Overall, 18,761 births occurred during the time-matched timeframe, and 18,569 births occurred during the month-matched sample. Births that resulted in neonatal mortality (36), those that refused the EPDS (230), and those with invalid EPDS scores (3) were excluded from the analysis. Patterns of missing data did not change over time. We utilized regression-based imputation to impute 56 missing values on the following covariates: women's age, race, ethnicity, educational attainment, marital status, and type of birth.

Our regression models control for a range of women and infant characteristics to account for known correlates of postpartum depression. Women's characteristics include race/ethnicity (white, Black, Hispanic, Asian, other), education (less than high school, high school diploma/GED, some college, four-year degree or higher), age (less than $20,20-34,35+$ ), pre-pregnancy health conditions (presence of one or more conditions), marital status (married, unmarried), delivery type (C-section, vaginal), and residence county (Hunterdon, Mercer, Middlesex, Monmouth, Ocean, Somerset, and other). Infant characteristics include preterm birth (less than 37 weeks and $37+$ weeks). Women with infants deceased prior to hospital discharge were excluded from the study. All respondent information collected is in accordance with the National Center for Health Statistics U.S. Birth Certificate Standard (CDC 2019).

Our analysis proceeds in three stages. First, we examine bivariate differences in depressive symptoms and sociodemographic and health risk factors over time. We then employ a series of Ordinary Least Squares regressions models. Because depressive symptoms exhibited high kurtosis levels in preliminary analyses, we utilize a natural log transformation. In the time-matched sample, our first model examines monthly differences in depressive symptomology, and our second model includes all other covariates. Our third model collapses all non-pandemic exposed groups into one category to retest the reduced form association between pandemic exposure and depressive symptoms, and our fourth model includes all additional covariates to ensure the previous associations were not being driven by compositional changes in sociodemographic and health-related factors across time. Models 5-8 replicate the previous four models with a month-matched sample.

Because we are modeling population data (all live births occurring in the central region of New Jersey in 2019 and early 2020), our substantive interpretations focus on the nature or direction of population parameters or regression coefficients. We do not report conventional statistical tests or p-values. P-values derived from sample statistics assess the probability of a chance association in the population. These inferences are important when the aim is to make population inferences from sample data. In this case, we have population data so there is no need to estimate population parameters with sample statistics.

\section{Results}

Over four thousand births occurred during the initial two months of the COVID-19 pandemic, with 2402 births occurring in March 2020 and 2123 occurring in April 2020. Table 1 shows that the average level of depressive symptoms was higher during March $2020($ mean $=2.72)$ than in both the time $($ mean $=2.59)$ and month-matched samples $($ mean $=2.61)$. The level of depressive symptoms, however, in April 2020 (mean =2.60) was similar to that of 
Table 1 Descriptive statistics by pandemic exposure for time-matched and month-matched samples

\begin{tabular}{|c|c|c|c|c|}
\hline & $\begin{array}{l}\text { Time-matched sample } \\
\text { No pandemic exposure (births } \\
\text { from September 2019-Febru- } \\
\text { ary 2020) }(n=14,006)\end{array}$ & $\begin{array}{l}\text { Month-matched sample } \\
\text { No pandemic exposure (births } \\
\text { from January 2019-April 2019) } \\
(\mathrm{n}=13,821)\end{array}$ & $\begin{array}{l}2020 \text { March pan- } \\
\text { demic exposure } \\
(n=2,402)\end{array}$ & $\begin{array}{l}2020 \text { April pandemic } \\
\text { exposure }(n=2,123)\end{array}$ \\
\hline & Mean/Prop. (SD) & Mean/Prop. (SD) & Mean/Prop. (SD) & Mean/Prop. (SD) \\
\hline $\begin{array}{l}\text { Postpartum depressive symp- } \\
\text { toms (natural } \log +.1 \text { ) }\end{array}$ & $2.55(3.07)$ & $2.61(3.11)$ & $2.72(3.12)$ & $2.60(3.03)$ \\
\hline \multicolumn{5}{|l|}{ Women's education } \\
\hline Less than high school & .10 & .11 & .10 & .08 \\
\hline High school & .26 & .26 & .25 & .25 \\
\hline Some college & .18 & .18 & .18 & .18 \\
\hline Four-year degree or higher & .46 & .45 & .47 & .49 \\
\hline \multicolumn{5}{|l|}{ Women's race } \\
\hline White & .55 & .56 & .56 & .58 \\
\hline Black & .09 & .09 & .09 & .08 \\
\hline Hipanic & .24 & .24 & .23 & .22 \\
\hline Asian & .11 & .11 & .11 & .11 \\
\hline Other & .01 & .01 & .01 & .01 \\
\hline \multicolumn{5}{|l|}{ Women's age } \\
\hline Age less than 20 & .02 & .02 & .02 & .02 \\
\hline Age between 20 and 34 & .73 & .73 & .72 & .71 \\
\hline Age between $35+$ & .25 & .24 & .26 & .27 \\
\hline $\begin{array}{l}\text { Prepregnancy health condi- } \\
\text { tion }\end{array}$ & .20 & .19 & .19 & .18 \\
\hline Unmarried & .74 & .74 & .74 & .75 \\
\hline C-section delivery & .29 & .29 & .29 & .30 \\
\hline Preterm birth & .08 & .08 & .09 & .07 \\
\hline \multicolumn{5}{|l|}{ County } \\
\hline Hunterdon & .02 & .03 & .03 & .03 \\
\hline Mercer & .14 & .13 & .13 & .12 \\
\hline Middlesex & .22 & .21 & .21 & .23 \\
\hline Monmouth & .18 & .18 & .18 & .19 \\
\hline Ocean & .29 & .29 & .28 & .24 \\
\hline Somerset & .07 & .07 & .06 & .07 \\
\hline Other & .08 & .08 & .10 & .13 \\
\hline
\end{tabular}

pre-pandemic time periods in both samples (mean $=2.59$ and 2.61). The proportion of births across counties differed somewhat across time periods in both samples with more births occurring in "other" counties (those not residing in the central region but delivering there). Further, the educational composition of women differed between the April pandemic group and those that gave birth in prior months in the time matched sample. These differences underscore the need to test how pandemic exposure is related to depressive symptoms after adjusting for these and other factors.

Model 1 in Table 2 shows that women who gave birth during the pandemic in March had higher levels of depressive symptoms than those who gave birth in September $(b=-0.09)$, October $(b=-0.08)$, November $(b=-0.11)$, December $(b=-0.019)$, January $(b=-0.03)$, or February $(b=-0.09)$. These same patterns persisted after controlling for all other covariates in Model 2. Models 3 and 4 combine all non-pandemic months together into one category to produce more stable estimates. These models show that women who gave birth during the pandemic in March, but not in April, had higher levels of depressive symptoms than those who gave birth prior to the pandemic (Model 4: $b=0.07$ ). Models 5-8 provide the same model specifications as above with the month-matched sample. These results are substantively similar to those presented in the first four models. The magnitude of this association is roughly equivalent to onethird the magnitude of having a preterm birth, a previously 
Table 2 Covid 19 pandemic exposure regressed on postpartum depressive symptoms

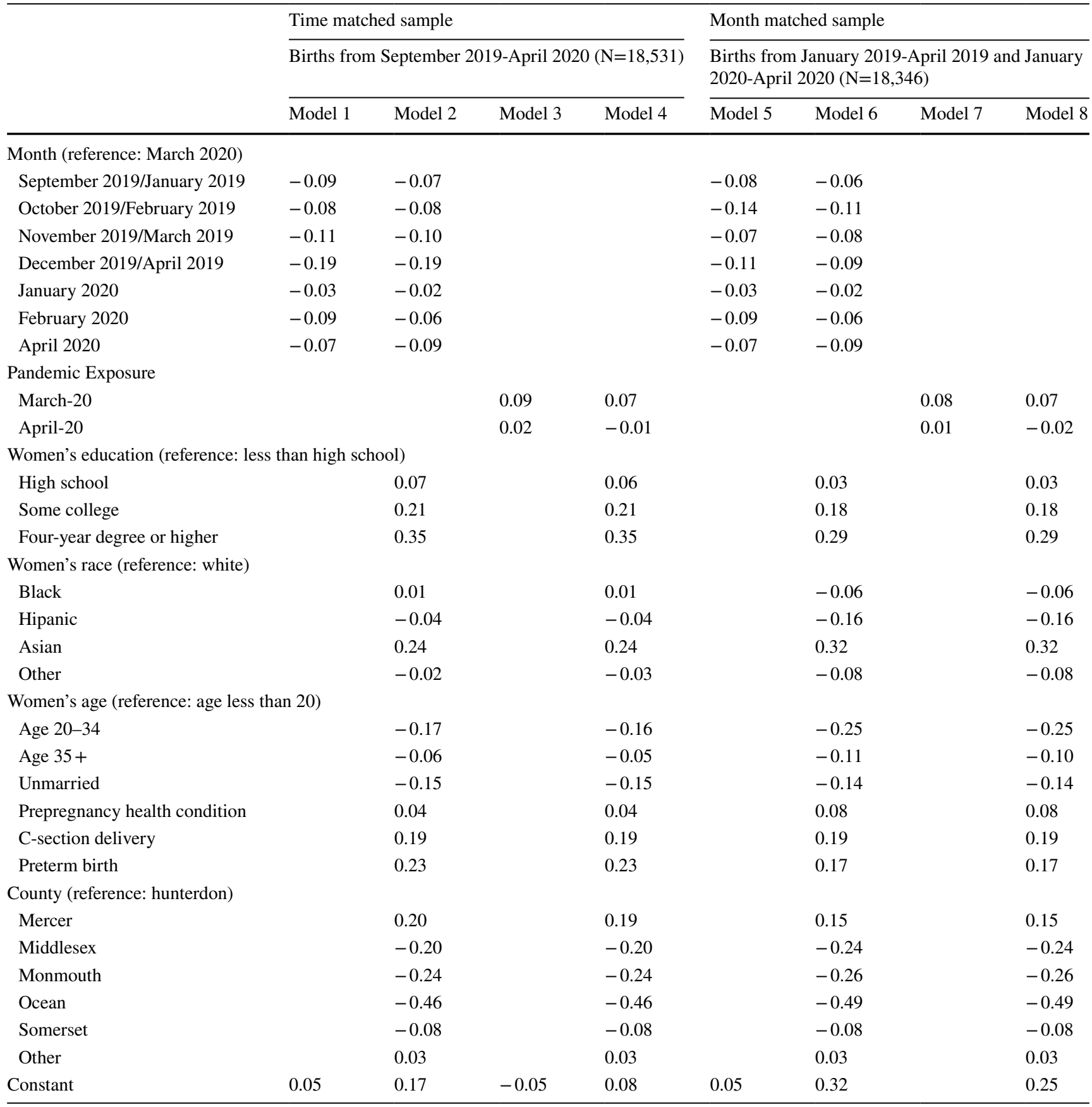

established predictor of postpartum depressive symptoms (Davis et al. 2003).

\section{Discussion}

Results from this population-based study suggest that giving birth during the first month of the COVID-19 pandemic was associated with more postpartum depressive symptoms while giving birth during the second month of the pandemic was unrelated to depressive symptomology. The former finding is consistent with the notion that the pandemic contributed to emotional distress by precipitating new and unique forms of stress and uncertainty while the latter finding suggests some habituation of pandemic stress or perhaps some form of resource mobilization on the part of pregnant women.

Pregnant women are not passive agents, they adapt behaviors and mobilize resources in order to effectively cope with ubiquitous stressors (Torche and Villarreal 2014; Currie 
and Rossin-Slater 2013). Two of the characteristics that make stress "stressful" include uncertainty and powerlessness (Pearlin and Bierman 2013) - two phenomenon that women giving birth during the onset of the pandemic likely experienced. Women who gave birth during the second month of the pandemic had more time to obtain information and design new courses of action to exercise some level of agency over their reproductive lives. Indeed, by late March blogs, social media posts, and news articles emerged on what to expect when you are expecting a "corona baby" (Martin 2020; Sinha 2020; Paluck 2020; Grace 2020). Equipped with the benefits of process time and information from experienced women, giving birth during April may have seemed less uncertain and less overwhelming than during March.

Our findings should be interpreted within the context of several limitations. While the pandemic can be thought of as exogenous to mother's characteristics and thus viewed as a type of natural experiment, threats to causal inference remain. For instance, it is possible that time trends in depressive symptomology that would have produced the same pattern of results reported here may have manifested even if the pandemic had never occurred. While our study design attempted to account for this possibility in several ways, we cannot offer definitive evidence that the pandemic was entirely responsible for the elevations in depressive symptoms. Second, we were not able to fully capture the extent to which women with mental health-linked characteristics disproportionately selected hospitals outside of central NJ or $\mathrm{NJ}$ altogether. For instance, our estimates would be biased if women with high levels of conscientiousness systematically chose to give birth outside of central New Jersey as a result of the pandemic. While such a scenario remains a limitation, the relatively stable demographics of women giving birth prior to and during the pandemic shown in Table 1 mitigate this concern.

\section{Public Health Implications}

Overall, this study provides evidence that the pandemic may put women at potentially heightened risk for PPD. Policies aimed at improving maternal health during the current pandemic and future public health crises should include additional funding and resources for perinatal mood disorders. New Jersey was the first state to enact legislation to provide education and screening for postpartum depression, including training clinicians to provide screening, referrals, and treatment for PPD. New Jersey continues to provide targeted trainings in hospitals, clinician's offices, conferences, and continuing medical education programs with the goal of reaching all clinicians who may be able to identify or treat women who suffer from PPD (Kozhimannil et al. 2011). During times of crisis, these education and support programs provide invaluable resources for women at risk. Moreover, in an age of mass technological advancement, opportunities for virtual resources create a space where women from across the state and beyond can come together and obtain the support they need. Given that health care professionals fail to ask about depression during the postpartum period in approximately $13 \%$ of women (Bauman et al. 2020), interventions along these lines could aid hundreds of thousands of families left to struggle without care.

Our finding that depressive symptoms were not elevated during the second month of the pandemic suggests that pregnant women may have found ways to adapt and mobilize resources to preserve their mental health. This latter finding may be considered unexpected and points to how little researchers know about behavioral responses and coping processes during pandemics. For this reason, researchers and clinicians should continue to monitor the mental health of women as the pandemic unfolds and place a heightened focus on understanding their agentic responses.

\section{Compliance with Ethical Standards}

Conflict of interest The authors have no conflicts to declare.

\section{References}

Almond, K. (2020). "At home or the hospital? Giving birth during a pandemic." CNN May https://www.cnn.com/interactive/2020/05/ health/coronavirus-pregnancy-birth-cnnphotos/index.html

Bauman, B. L., Ko, J. Y., Cox, S., D’Angelo, D. V., Warner, L., Folger, S., et al. (2020). Vital Signs: Postpartum Depressive Symptoms and Provider Discussions About Perinatal Depression - United States, 2018. MMWR. Morbidity and Mortality Weekly Report, 69(19), 575-581. https://doi.org/10.15585/mmwr.mm6919a2.

Businelle, M. S., Kendzor, D. E., Reitzel, L. R., Vidrine, J. I., Castro, Y., Mullen, P. D., et al. (2012). Pathways Linking Socioeconomic Status and Postpartum Smoking Relapse. Annals of Behavioral Medicine, 45(2), 180-191. https://doi.org/10.1007/s1216 0-012-9434-x.

Cox, J. L., Holden, J. M., \& Sagovsky, R. (1987). Detection of Postnatal Depression. British Journal of Psychiatry, 150(6), 782-786. https://doi.org/10.1192/bjp.150.6.782.

Currie, J., \& Rossin-Slater, M. (2013). Weathering the storm: Hurricanes and birth outcomes. Journal of Health Economics, 32(3), 487-503. https://doi.org/10.1016/j.jhealeco.2013.01.004.

Davis, L., Edwards, H., Mohay, H., \& Wollin, J. (2003). The impact of very premature birth on the psychological health of mothers. Early Human Development, 73(1-2), 61-70. https://doi.org/10.1016/ s0378-3782(03)00073-2.

Downs, D. S., DiNallo, J. M., \& Kirner, T. L. (2008). Determinants of Pregnancy and Postpartum Depression: Prospective Influences of Depressive Symptoms, Body Image Satisfaction, and Exercise Behavior. Annals of Behavioral Medicine, 36(1), 54-63. https:// doi.org/10.1007/s12160-008-9044-9.

Durankuş, F., \& Aksu, E. (2020). Effects of the COVID-19 pandemic on anxiety and depressive symptoms in pregnant women: a 
preliminary study. The Journal of Maternal-Fetal \& Neonatal Medicine. https://doi.org/10.1080/14767058.2020.1763946.

Gibson, J., McKenzie-McHarg, K., Shakespeare, J., Price, J., \& Gray, R. (2009). A systematic review of studies validating the Edinburgh Postnatal Depression Scale in antepartum and postpartum women. Acta Psychiatrica Scandinavica, 119(5), 350-364. https://doi.org /10.1111/j.1600-0447.2009.01363.x.

Grace, A. (2020). "Coronavirus and pregnancy: An expecting N.J. mom's experience during the unexpected crisis." NJ.com April $21 \mathrm{https}: / / w w w . n j . c o m / c o r o n a v i r u s / 2020 / 04 /$ coronavirus-andpregnancy-an-expecting-nj-moms-experience-during-the-unexp ected-crisis.html

Grote, N. K., \& Bledsoe, S. E. (2007). Predicting Postpartum Depressive Symptoms in New Mothers: The Role of Optimism and Stress Frequency during Pregnancy. Health \& Social Work, 32(2), 107 118. https://doi.org/10.1093/hsw/32.2.107.

Haight, S. C., Byatt, N., Moore Simas, T. A., Robbins, C. L., \& Ko, J. Y. (2019). Recorded Diagnoses of Depression During Delivery Hospitalizations in the United States, 2000-2015. Obstetrics \& Gynecology, 133(6), 1216-1223. https://doi.org/10.1097/ aog.0000000000003291.

Knoll C. (2020). "I'm Officially Scared": Giving Birth in a Hospital During a Pandemic. The New York Times May 5. "I'm Officially Scared": Giving Birth in a Hospital During a Pandemic. The New York Times May 5. https://www.nytimes.com/2020/05/05/nyreg ion/coronavirus-pregnant-birth-quarantine.html

Kozhimannil, K. B., Adams, A. S., Soumerai, S. B., Busch, A. B., \& Huskamp, H. A. (2011). New Jersey's Efforts To Improve Postpartum Depression Care Did Not Change Treatment Patterns For Women On Medicaid. Health Affairs, 30(2), 293-301. https://doi. org/10.1377/hlthaff.2009.1075.

Martin, N. (2020). "What Coronavirus Means for Pregnancy, and Other Things New and Expecting Mothers Should Know" ProPublica March 19 https://www.propublica.org/article/coronavirus-andpregnancy-expecting-mothers-q-and-a

Matthey, S., Barnett, B., Kavanagh, D. J., \& Howie, P. (2001). Validation of the Edinburgh Postnatal Depression Scale for men, and comparison of item endorsement with their partners. Journal of Affective Disorders, 64(2-3), 175-184. https://doi.org/10.1016/ s0165-0327(00)00236-6.

McClelland, SW. (2020). "Don't Be Afraid of Giving Birth in a New York Hospital: At this point, it's safer than going elsewhere or giving birth at home." The New York Times April 28 https://www. nytimes.com/2020/04/28/opinion/coronavirus-birth-nyc-hospitals. html

O'Hara, M. W. (2009). Postpartum depression: what we know. Journal of Clinical Psychology, 65(12), 1258-1269. https://doi. org/10.1002/jclp.20644.
Paluck, Betsy. (2020). "I gave birth by myself during the coronavirus pandemic, but I wasn't alone." The Washington Post April 30 , 2020 https://www.washingtonpost.com/lifestyle/2020/04/30/igave-birth-by-myself-during-covid-pandemic-i-wasnt-alone/

Pearlin, L. I., \& Bierman, A. (2013). Current Issues and Future Directions in Research into the StressProcess. In C. S. Aneschensel, J. C. Phelan, \& A. Bierman (Eds.), Handbook of the Sociology of Mental Health (pp. 325-340). New York, NY: Springer.

Pfeiffer, S. (2020). "Pregnant Women Worry About Pandemic's Impact On Labor, Delivery And Babies." NPR March 30. https://www. npr.org/2020/03/30/823575358/pregnant-women-worry-about -pandemics-impact-on-labor-delivery-and-babies

Robertson, E., Grace, S., Wallington, T., \& Stewart, D. E. (2004). Antenatal risk factors for postpartum depression: a synthesis of recent literature. General Hospital Psychiatry, 26(4), 289-295. https:// doi.org/10.1016/j.genhosppsych.2004.02.006.

Rocca-Ihenacho, L., \& Alonso, C. (2020). Where do women birth during a pandemic? Changing perspectives on Safe Motherhood during the COVID-19 pandemic. Journal of Global Health Science. https://doi.org/10.35500/jghs.2020.2.e4.

Sinha, S. (2020). "Pregnant in a Pandemic? These 5 Mothers of Newborns Have Advice." The New York Times. May 10, 2020 https:// www.nytimes.com/2020/05/10/us/coronavirus-giving-birth-newmothers.html

Stein, S. (2020). "You See Your Smallness": On Giving Birth in a Pandemic. Vogue May 5, 2020 https://www.vogue.com/article/ giving-birth-coronavirus-pandemic-advice

Swendsen, J. D., \& Mazure, C. M. (2006). Life Stress as a Risk Factor for Postpartum Depression: Current Research and Methodological Issues. Clinical Psychology: Science and Practice, 7(1), 17-31. https://doi.org/10.1093/clipsy.7.1.17.

Torche, F., \& Villarreal, A. (2014). Prenatal Exposure to Violence and Birth Weight in Mexico. American Sociological Review, 79(5), 966-992. https://doi.org/10.1177/0003122414544733.

Wisner, K. L., Chambers, C., \& Sit, D. K. Y. (2006). Postpartum Depression. JAMA, 296(21), 2616. https://doi.org/10.1001/ jama.296.21.2616.

Yim, I. S., Tanner Stapleton, L. R., Guardino, C. M., Hahn-Holbrook, J., \& Dunkel Schetter, C. (2015). Biological and Psychosocial Predictors of Postpartum Depression: Systematic Review and Call for Integration. Annual Review of Clinical Psychology, 11(1), 99-137. https://doi.org/10.1146/annurev-clinpsy-101414-020426.

Publisher's Note Springer Nature remains neutral with regard to jurisdictional claims in published maps and institutional affiliations. 